\title{
Surveillance and characteristics of food-borne outbreaks in the Netherlands, 2006 to 2019
}

Ingrid HM Friesema1, Ife A Slegers-Fitz-James² , Ben Wit² , Eelco Franz ${ }^{1}$

1. Epidemiology and Surveillance of Infectious Diseases, Centre for Infectious Disease Control, National Institute for Public Health and the Environment (RIVM), Bilthoven, the Netherlands

2. Dutch Food and Consumer Product Safety Authority (NVWA), Utrecht, the Netherlands

Correspondence: Ingrid Friesema (ingrid.friesema@rivm.nl)

Background: A wide variety of pathogens can cause disease in humans via consumption of contaminated food. Although food-borne outbreaks only account for a small part of the food-borne disease burden, outbreak surveillance can provide insights about the pathogens, food products implied as vehicle, points of contamination, and the settings in which transmission occurs. Aim: To describe the characteristics of food-borne outbreaks registered between 2006 and 2019 in the Netherlands. Methods: All reported outbreaks in which the first case occurred during 2006-19 were analysed. We examined the number of outbreaks, cases and setting by year, aetiology, type of evidence and food commodities. Results: In total, 5,657 food-borne outbreaks with 27,711 cases were identified. The contaminated food product could be confirmed in 152 outbreaks (2.7\%); in 514 outbreaks (9.1\%), a pathogen was detected in cases and/or environmental swabs. Norovirus caused most outbreaks $(205 / 666)$ and most related cases $(4,436 / 9,532)$, followed by Salmonella spp. (188 outbreaks; 3,323 cases) and Campylobacter spp. (150 outbreaks; 601 cases). Bacillus cereus was most often found in outbreaks with a confirmed food vehicle (38/152). Additionally, a connection was seen between some pathogens and food commodities. Public eating places were most often mentioned as a setting where the food implicated in the outbreak was prepared. Conclusion: Long-term analysis of food-borne outbreaks confirms a persistent occurrence. Control and elimination of foodborne illness is complicated since multiple pathogens can cause illness via a vast array of food products and, in the majority of the outbreaks, the pathogen remains unknown.

\section{Introduction}

A wide variety of pathogens can cause disease in humans through the consumption of contaminated food [1-3]. Contamination of food can occur at any point from farm to table, as a result of improper hygiene, handling, storage or preparation, and the broad range of food products that can be contaminated adds to the complexity. An estimated 652,000 cases of infectious diseases because of contaminated food occurred in 2018 in the Netherlands, leading to around EUR 171 million in costs [4]. This figure and corresponding costs have remained at the same level since $2009[4,5]$. The exact number of cases remains unknown; only a minority of food-borne cases is captured by surveillance systems since most infections are relatively mild and no diagnostic testing is performed. Furthermore, not all food-borne infections are systematically monitored.

Although recognised food-borne outbreaks only account for a small part of the food-borne disease burden, they can provide insight into the pathogens causing outbreaks, food products implied as vehicles, points of contamination, and settings in which transmission occurs $[6,7]$. Determination of the contaminated food product is difficult, especially in sporadic cases, because of varying incubation periods in which many exposures occurred, as well as recall bias. Outbreaks offer the opportunity to gather consumption data from more than one case and to perform a comparison with controls, which increases the chance of finding the contaminated food item. Analysis of data over a longer period also offers the opportunity to describe trends in food-borne outbreaks, to identify new and emerging food-borne pathogens and specific pathogen-food combinations, and to examine the public health importance of pathogens, which can be used to improve food safety $[6,8]$.

The aim of this study is to describe the characteristics of food-borne outbreaks registered between 2006 and 2019 in the Netherlands in order to provide a better understanding of food-borne outbreaks and to guide efforts to control, reduce and prevent future foodborne illness. 
Number of food-borne outbreaks $(n=5,657)$ and related human cases $(n=27,711)$ per year, the Netherlands, 2006-2019

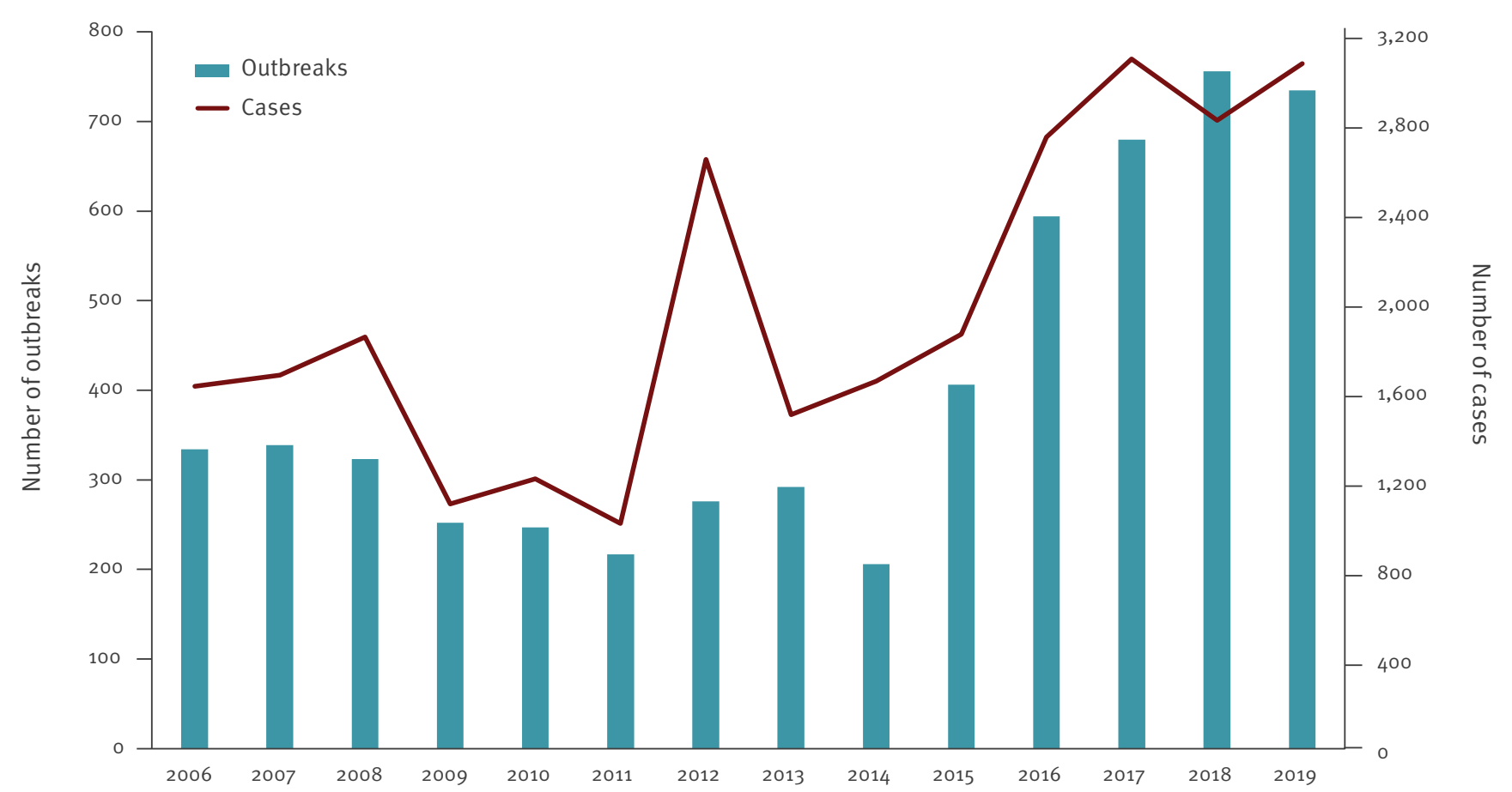

Year

Data is composed of the outbreaks reported by PHS, detected through disease-specific national surveillance systems, reported by the NVWA, and the outbreaks found via the additional search. Outbreaks reported via more than one pathway are combined into one outbreak.

\section{Methods}

Surveillance systems for food-borne outbreaks in the Netherlands

In the Netherlands, three main surveillance pathways for the detection of food-borne outbreaks exist.

Firstly, professionals, such as doctors and microbiologists, mandatorily report outbreaks to the regional public health service (PHS) when there are two or more human cases with the same disease and/or infection, and with a probable link to the same food source. The PHS investigates the outbreak, often together with the Dutch Food Safety Authority (Nederlandse Voedsel en Waren Autoriteit (NVWA)). Each PHS notifies all food-borne outbreaks to the National Institute for Public Health and the Environment (Rijksinstituut voor Volksgezondheid en Milieu (RIVM)) as soon as possible. The 25 PHS report these outbreaks via a digital notification system that went online in 2003.

Secondly, outbreaks can be detected via sequence data gathered within the national disease-specific surveillance systems for Salmonella, Listeria monocytogenes, Shiga toxin-producing Escherichia coli (STEC) and hepatitis A. With such events, the RIVM coordinates and analyses the outbreak on behalf of all PHS. Also, outbreaks detected simultaneously in more than one PHS region can shift to this pathway. Since 2012, national outbreaks have been manually added by the RIVM to the same digital notification system as used by the PHS.

Thirdly, a pathway exists for citizens who suspect to have become ill following consumption of food or drinks. Citizens can report directly to the NVWA, which is recorded in a standardised form. When sufficient information is given, the NVWA will investigate the possible food-borne outbreak. The NVWA has used the same online system as the PHS since 2006 to report outbreaks to the RIVM, although the system does not facilitate joint reports. Up to 2014, all outbreaks in which food samples or environmental swabs were taken were reported. These criteria were broadened in 2015 to all non-anonymous reports of outbreaks, regardless whether food/environmental samples were taken. Basic laboratory investigations were typically performed for suspected bacterial contamination. If other contamination were suspected, like the presence of viruses or scombroid toxins, these analyses were added. However, results of virus investigations, both in food and environmental swabs, were mainly registered in a different laboratory system within the NVWA, which were not standardly added to the reports. Since 
2012, efforts have increased to also report the virus results of these outbreaks.

For our analyses, all outbreaks reported through these three pathways in which the first case occurred during 2006-19 were combined into one database, where paired reports of one outbreak were merged.

\section{Additional data on food-borne outbreaks}

A parallel literature search of publications and grey literature, as well as internal databases held at RIVM, revealed some outbreaks that were not reported through one of the surveillance pathways. The largest group of missing outbreaks were national outbreaks occurring before 2012 .

\section{Outbreak classification}

The type of evidence leading to the suspicion of the food vehicle was determined. If no pathogen could be established in cases or food, the outbreak was categorised as 'not confirmed'. When environmental swabs were taken and tested positive for norovirus or rotavirus, and no foods tested positive, the outbreak was categorised as 'positive environmental swabs', regardless of whether cases also tested positive. Outbreaks for which a pathogen was identified in cases, were categorised as 'confirmed in case(s)', in the absence of another indicator. An outbreak was considered to have a confirmed food vehicle when a pathogen was detected in a food product or a pathogen was found in cases, in conjunction with strong epidemiological evidence from the outbreak investigation implying one food product.

If Bacillus cereus, Staphylococcus aureus or Clostridium perfringens were detected, the number of colony forming units (cfu) should exceed the legal standard of $100,000 \mathrm{cfu}$ per gram or millilitre food before considered harmful [9]. A cut-off of $100 \mathrm{cfu}$ was used for Listeria monocytogenes [10]. Detections below the limits were registered and analysed as 'not confirmed'. We calculated the number of outbreaks, cases, and counts per setting by aetiology and type of evidence. We also examined the number of outbreaks and cases per year for Campylobacter spp., Salmonella sp p. and norovirus. All food products implicated in the confirmed food-borne outbreaks were assigned to one of 11 food commodities, i.e. fish, shellfish, red meat (pork or beef), poultry, eggs, dairy, fruit/vegetables, cereals/pasta/rice, pastry/cookies, soup/sauce, and composed products (dishes with a mixture of ingredients, for example vegetables, meat, and/or rice); food commodity-pathogen pairs were examined.

\section{Analyses}

The data from the three surveillance pathways entered in the digital notification system was extracted into Microsoft Excel and all additional food-borne outbreaks found in the literature search were added to the Excel database. Analyses were done using SAS
9.4 (SAS Institute, Cary, North Carolina, United States (US)).

\section{Ethical statement}

Ethical approval was not needed as all information gathered in the database are aggregated on outbreak level and do not contain data on individuals.

\section{Results}

\section{Outbreak overview}

During 2006-19, a total of 5,657 food-borne outbreaks with 27,711 cases were identified. An average of 404 (range: 206-756) outbreaks with 1,979 (range: 1,0063,080 ) cases was reported each year (Figure 1). The mean number of cases per outbreak was 4.9 (range: $1-1,149)$. Most outbreaks were reported to the NVWA (5,367 outbreaks and 25,659 cases) compared with PHS notifications (523 outbreaks and 8,844 cases). One outbreak consisted of a single Dutch case as part of an international outbreak.

Within the PHS notifications, a decrease in reports was observed between 2006-12 (40-49 outbreaks/year) and 2013-19 (27-38 outbreaks/year) without a change in criteria or other clear reason. In contrast, the number of registered outbreaks by the NVWA increased substantially after changing the criteria in 2015 , i.e. from 251 (range: $185-313$ ) outbreaks per year in 2006-14 to 622 (range: 398-736) outbreaks per year in 2015-19. However, the percentage of outbreaks registered by the NVWA in which a pathogen was reported dropped from $10.7 \%$ in $2006-14$ to $5.3 \%$ in $2015-19$.

In total, 290 outbreaks were only reported as a PHS notification, 5,134 only via the NVWA, and 233 in both systems. In the PHS-only notifications, a pathogen was detected in $86.6 \%(n=251)$ of cases, $0.7 \%$ $(n=2)$ in food/environment, or both in $1.7 \%(n=5)$. In NVWA-only reports, a pathogen was detected in $1.2 \%$ $(n=62), 3.2 \%(n=164)$, and $0.2 \%(n=11)$, respectively, for cases, food/environment or both. Finally, the distribution within outbreaks reported by both institutions was $41.2 \%(n=96), 8.6 \%(n=20)$, and $23.6 \%(n=55)$. Strong epidemiological evidence existed in nine PHS notifications $(3.1 \%)$ and in 14 outbreaks reported by both $(6.0 \%)$. A positive food product was found in seven PHS notifications (2.4\%), 89 NVWA-only reports (1.7\%) and 33 outbreaks reported by both (14.2\%).

Differences were observed based on the setting of the outbreak. In PHS notifications ( $n=290)$, private home $(n=102 ; 35.2 \%)$, infected abroad $(n=70 ; 24.1 \%)$ and restaurant/deli/cafeteria $(n=51 ; 17.6 \%)$ are most mentioned, whereas restaurant/deli/cafeteria ( $n=4,181$; $81.4 \%)$, plant/facility $(n=370 ; 7.2 \%)$ and private home $(n=250 ; 4.9 \%)$ are most mentioned in NVWAonly reports $(n=5,134)$, and restaurant/deli/cafeteria $(n=2 ; 48.1 \%)$, catering $(n=37 ; 15.9 \%)$ and plant/ 


\section{FIGURE 2}

Number of food-borne outbreaks and related human cases per year for Campylobacter spp. ( $\mathrm{n}=150)$, Salmonella spp. $(n=188)$, and norovirus $(n=205)$, the Netherlands, 2006-2019

A. Campylobacter spp.

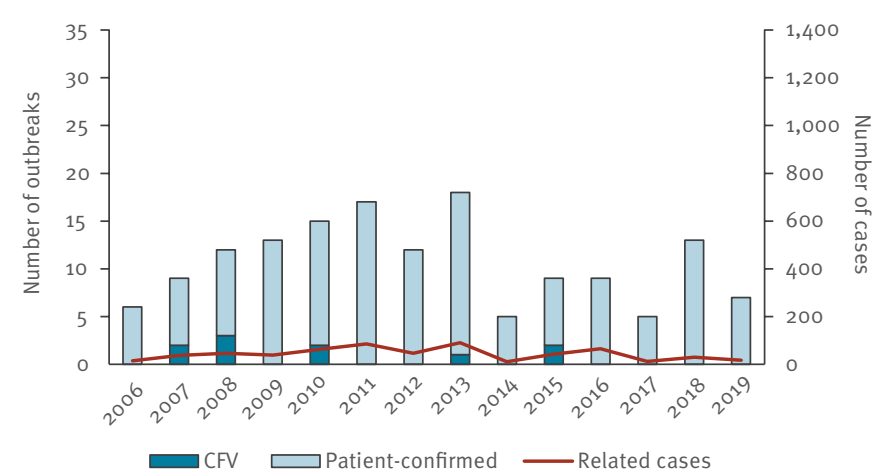

\section{Norovirus}

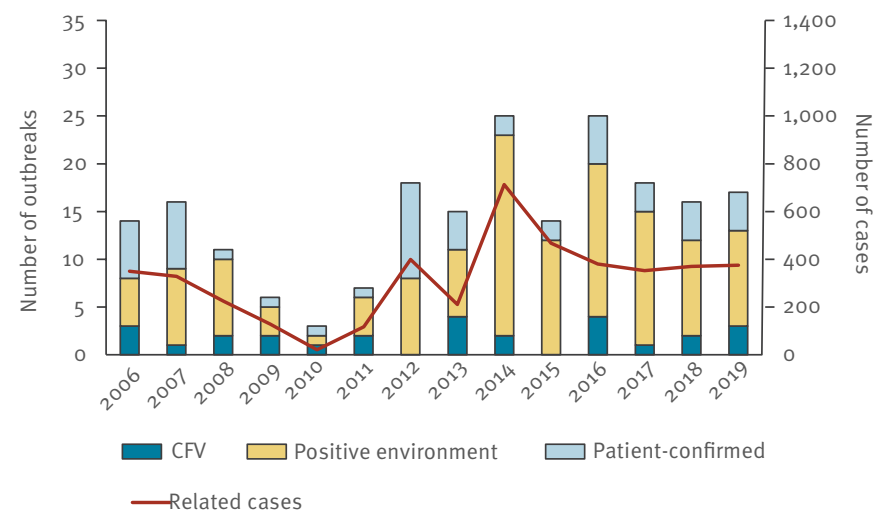

B. Salmonella spp.

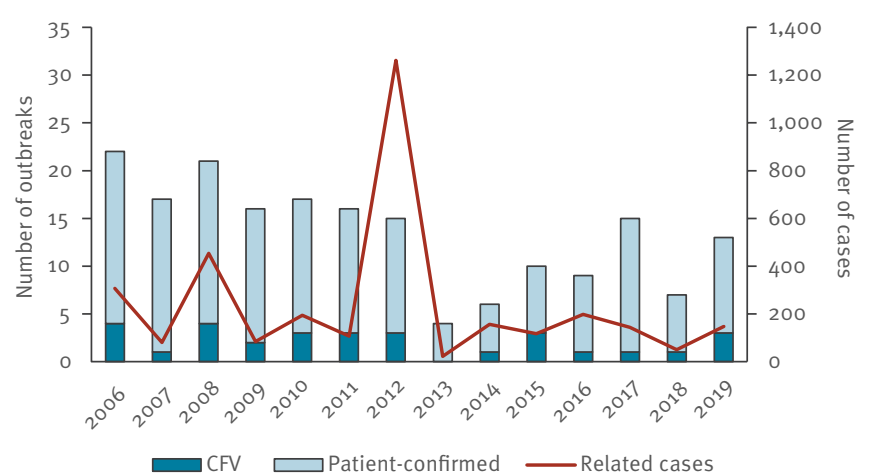

CFV $\square$ Patient-confirmed $\longrightarrow$ Related cases

CFV: confirmed food vehicle.

Patient-confirmed (all panels) indicates that the pathogen was confirmed only in case(s). Positive environment (yellow bars, panel C) indicate positive environmental swabs.

facility ( $n=30 ; 12.9 \%$ ) in outbreaks reported by both $(n=233)$.

\section{Aetiology}

In 666 (11.8\%) of the 5,657 outbreaks, a pathogen was reported to be detected in food, the environment and/ or in cases (Table 1). The food product causing the outbreak could be confirmed in 152 outbreaks (22.8\%); in the remaining 514 outbreaks (77.2\%), a pathogen was only detected in cases and/or environmental swabs. The mean number of cases per outbreak with a confirmed food vehicle was 23.4 (range: 2-1,149) cases, compared with 22.5 (range: $2-150$ ) cases with positive environmental swabs, 8.0 (range: 1-195) cases with a pathogen detected in patients, and 3.6 (range: $2-160$ ) cases in outbreaks without a pathogen identified.

Norovirus caused most outbreaks and most related cases, followed by Salmonella spp. and Campylobacter spp (Figure 2). The mean number of cases per outbreak is lower for Campylobacter spp. (4 cases/outbreak) compared with norovirus (22 cases/outbreak) and Salmonella spp. (18 cases/ outbreak). The three largest outbreaks all were caused by Salmonella: in 2012 due to Salmonella Thompson in smoked salmon with 1,149 reported cases [11], in 2006 due to Salmonella Typhimurium in cheese with 224 cases [12] and in 2008 due to Salmonella Enteritidis with 195 cases, most likely due to eggs although this was not confirmed. Recently, Salmonella outbreaks are less often seen; only four Salmonella outbreaks during 2013 and between six and 15 outbreaks in the years 2014-19 were observed, compared with between 15 and 22 outbreaks per year in 200612. Campylobacter outbreaks are less reported since 2014 compared with the period 2006-13. Reports of norovirus outbreaks have increased since 2012, primarily detected in environmental swabs. 
TABLE 1

Number and percentage of food-borne outbreaks $(n=5,657)$ and related human cases $(n=27,711)$, by aetiology and confirmation of food vehicle, the Netherlands, 2006-2019

\begin{tabular}{|c|c|c|c|c|c|c|c|c|c|c|c|}
\hline \multirow{4}{*}{ Aetiology } & \multicolumn{5}{|c|}{$\begin{array}{l}\text { Outbreaks } \\
(n=5,657)\end{array}$} & \multicolumn{6}{|c|}{$\begin{array}{c}\text { Cases } \\
(n=27,711)\end{array}$} \\
\hline & \multirow{3}{*}{$\begin{array}{l}\text { Confirmed } \\
\text { food } \\
\text { vehicle }\end{array}$} & \multirow{3}{*}{ Other } & \multicolumn{3}{|c|}{ Total } & \multirow{3}{*}{$\begin{array}{l}\text { Confirmed } \\
\text { food } \\
\text { vehicle }\end{array}$} & \multirow{3}{*}{ Other } & \multicolumn{4}{|c|}{ Total } \\
\hline & & & \multirow{2}{*}{$\mathrm{n}$} & \multirow{2}{*}{$\%$} & \multirow{2}{*}{$\begin{array}{c}\text { Outbreaks } \\
\text { per year } \\
\text { (range) }\end{array}$} & & & \multirow{2}{*}{$\mathrm{n}$} & \multirow{2}{*}{$\%$} & \multicolumn{2}{|c|}{$\begin{array}{l}\text { Cases per } \\
\text { outbreak }\end{array}$} \\
\hline & & & & & & & & & & Mean & Range \\
\hline Bacillus cereus & 33 & 2 & 35 & 0.6 & $0-6$ & 227 & 7 & 234 & 0.8 & 7 & $2-90$ \\
\hline Clostridium spp./C. botulinum & 0 & 2 & 2 & 0.04 & $0-1$ & 0 & 11 & 11 & 0.04 & 6 & $3-8$ \\
\hline Clostridium perfringens & 5 & 0 & 5 & 0.1 & $0-2$ & 192 & 0 & 192 & 0.7 & 38 & $2-180$ \\
\hline Staphylococcus aureus & 11 & 1 & 12 & 0.2 & $0-5$ & 62 & 55 & 117 & 0.4 & 10 & $2-55$ \\
\hline Campylobacter spp. (total) & 10 & 140 & 150 & 2.7 & $5-18$ & 77 & 524 & 601 & 2.2 & 4 & $2-30$ \\
\hline Campylobacter coli & 0 & 3 & 3 & 0.1 & $0-1$ & 0 & 10 & 10 & 0.04 & 3 & $2-4$ \\
\hline Campylobacter fetus & 1 & 0 & 1 & 0.0 & $0-1$ & 5 & 0 & 5 & 0.02 & 5 & $5-5$ \\
\hline Campylobacter jejuni & 3 & 76 & 79 & 1.4 & $0-11$ & 27 & 251 & 278 & 1.0 & 4 & $2-16$ \\
\hline Campylobacter spp. & 6 & 61 & 67 & 1.2 & $2-11$ & 45 & 263 & 308 & 1.1 & 5 & $2-30$ \\
\hline Listeria monocytogenes & 9 & 2 & 11 & 0.2 & $0-4$ & 64 & 4 & 68 & 0.2 & 6 & $2-35$ \\
\hline Salmonella spp. (total) & 30 & 158 & 188 & 3.3 & $4-22$ & 2,257 & 1,066 & 3,323 & 12.0 & 18 & $1^{\mathrm{c}}-1,149$ \\
\hline Salmonella Enteritidis & 10 & 47 & 57 & 1.0 & $1-9$ & 343 & 431 & 774 & 2.8 & 14 & $2-195$ \\
\hline Salmonella Typhimurium & 7 & 18 & 25 & 0.4 & $0-6$ & 513 & 255 & 768 & 2.8 & 31 & $2-100$ \\
\hline Other Salmonella serotypes & 10 & 10 & 20 & 0.4 & $0-4$ & 1,377 & 93 & 1,470 & $5 \cdot 3$ & 74 & $15-1,149$ \\
\hline Salmonella spp. & 3 & 83 & 86 & 1.5 & $0-10$ & 24 & 287 & 311 & 1.1 & 4 & $2-26$ \\
\hline Shigella spp. & 0 & 7 & 7 & 0.1 & $0-2$ & 0 & 203 & 203 & 0.7 & 29 & $2-162$ \\
\hline STEC & 5 & 6 & 11 & 0.2 & $0-2$ & 82 & 21 & 103 & 0.4 & 9 & $2-41$ \\
\hline Hepatitis A virus & 5 & 5 & 10 & 0.2 & $0-2$ & 62 & 36 & 98 & 0.4 & 10 & $3-15$ \\
\hline Norovirus (total) & 27 & 178 & 205 & 3.6 & $3-25$ & 449 & 3,987 & 4,436 & 16.0 & 22 & $2-150$ \\
\hline Norovirus GI & 4 & 12 & 16 & 0.3 & $0-3$ & 96 & 345 & 441 & 1.6 & 28 & $2-74$ \\
\hline Norovirus GI and GII & 3 & 4 & 7 & 0.1 & $0-2$ & 53 & 93 & 146 & 0.5 & 21 & $3-47$ \\
\hline Norovirus GII & 5 & 43 & 48 & 0.8 & $0-9$ & 40 & 1,018 & 1,058 & 3.8 & 22 & $2-150$ \\
\hline Norovirus & 15 & 119 & 134 & 2.4 & $2-19$ & 260 & 2,531 & 2,791 & 10.1 & 21 & $2-132$ \\
\hline Scombroid toxin/histamine & 11 & 3 & 14 & 0.2 & $0-4$ & 75 & 6 & 81 & 0.3 & 6 & $2-24$ \\
\hline Other pathogens ${ }^{a}$ & 1 & 6 & 7 & 0.1 & $0-2$ & 3 & 21 & 24 & 0.1 & 3 & $2-9$ \\
\hline Two pathogens ${ }^{b}$ & 5 & 4 & 9 & 0.2 & $0-2$ & 15 & 26 & 41 & 0.1 & 5 & $2-13$ \\
\hline All known & 152 & 514 & 666 & 11.8 & NA & 3,565 & 5,967 & 9,532 & $34 \cdot 4$ & 14 & $1^{\mathrm{c}}-1,149$ \\
\hline All unknown & NA & NA & 4,991 & 88.2 & NA & NA & NA & 18,179 & 65.6 & 4 & $2-160$ \\
\hline
\end{tabular}

GI: genogroup I; GII: genogroup II; NA: not applicable; other: food vehicle not confirmed OR positive environmental swabs OR pathogen confirmed in case(s); STEC: Shiga toxin-producing Escherichia coli.

${ }^{a}$ Other pathogens were found in a confirmed food vehicle (Vibro parahaemolyticus, one outbreak) or in other outbreaks including Yersinia enterocolitica (two outbreaks), rotavirus (one outbreak; positive environmental swab), Giardia (two outbreaks), and tapeworm (one outbreak).

b Two pathogens were found in a confirmed food vehicle in five outbreaks: B. cereus and C. perfringens (two outbreaks), B. cereus and S. aureus (two outbreaks), and B. cereus and S. Enteritidis and for other in four outbreaks: C. jejuni and norovirus, C. jejuni and STEC, S. Typhimurium and STEC, Dientamoeba fragilis and Blastocystis hominis.

c One case was an international outbreak with a single Dutch patient.

Rows in bold text indicate the subtotal for each particular pathogen or pathogen group. Rows that are not in bold are subgroups of a pathogen based on typing results. 
Number and percentage of food-borne outbreaks by place where food was prepared, and confirmation of pathogen, the Netherlands, 2006-2019 $(\mathrm{n}=5,657)$

\begin{tabular}{|l|c|c|c|c|c|c|c|c|c|}
\hline \multirow{2}{*}{ Location } & \multicolumn{2}{|c|}{$\begin{array}{c}\text { Confirmed food } \\
\text { vehicle }\end{array}$} & \multicolumn{2}{c|}{$\begin{array}{c}\text { Positive environmental } \\
\text { swabs }\end{array}$} & \multicolumn{2}{c|}{$\begin{array}{c}\text { Pathogen } \\
\text { confirmed in } \\
\text { case(s) }\end{array}$} & \multicolumn{2}{c|}{$\begin{array}{c}\text { Pathogen not } \\
\text { confirmed }\end{array}$} \\
\cline { 2 - 13 } & $\mathrm{n}$ & $\%$ & $\mathrm{n}$ & $\%$ & $\mathrm{n}$ & $\%$ & $\mathrm{n}$ & $\%$ \\
\hline Restaurant/deli/cafeteria & 90 & 2.1 & 83 & 1.9 & 125 & 2.9 & 4,046 & 93.1 & 4,344 \\
\hline Entertainment/party location & 2 & 4.7 & 6 & 14.0 & 11 & 25.6 & 24 & 55.8 & 43 \\
\hline Catering & 8 & 9.1 & 22 & 25.0 & 10 & 11.4 & 48 & 54.5 & 88 \\
\hline Fair/mobile service & 1 & 0.9 & 0 & 0.0 & 1 & 0.9 & 104 & 98.1 & 106 \\
\hline Farm (shop) & 7 & 58.3 & 0 & 0.0 & 1 & 8.3 & 4 & 33.3 & 12 \\
\hline Plant or facility & 26 & 6.3 & 2 & 0.5 & 24 & 5.8 & 359 & 87.3 & 411 \\
\hline Institution & 2 & 3.5 & 8 & 14.0 & 13 & 22.8 & 34 & 59.6 & 57 \\
\hline Private home & 10 & 2.7 & 0 & 0.0 & 106 & 29.1 & 248 & 68.1 & 364 \\
\hline Infected abroad & 2 & 2.8 & 0 & 0.0 & 68 & 95.8 & 1 & 1.4 & 71 \\
\hline Other/unknown & 4 & 2.5 & 7 & 4.3 & 27 & 16.8 & 123 & 76.4 & 161 \\
\hline Total & 152 & 2.7 & 128 & 2.3 & 386 & 6.8 & 4,991 & 88.2 & 5,657 \\
\hline
\end{tabular}

B. cereus, C. perfringens, and $S$. aureus are rarely diagnosed in cases, and almost only found in food. $B$. cereus is most often found in outbreaks with a confirmed food vehicle, followed by Salmonella spp. and norovirus (Table 1 ).

\section{Outbreak setting}

Restaurants/deli/cafeteria were most frequently implicated in food-borne outbreaks (Table 2), and linked to $81.1 \%$ of not-confirmed outbreaks, followed by plant or facility $(7.2 \%)$ and private home $(5.0 \%)$. Of the confirmed food-borne outbreaks, restaurants/deli/cafeteria are mentioned in $59.2 \%$ of the outbreaks, followed by plant or facility (17.1\%) and private home (6.6\%). The restaurants/deli/cafeteria setting was found in $64.8 \%$ outbreaks with positive environmental swabs, followed by catering (17.2\%) and institutions (6.3\%); in outbreaks with confirmed cases, $32.4 \%$ were found in restaurants/deli/cafeteria, $27.5 \%$ in private home, and $17.6 \%$ were infected abroad.

\section{Food products}

Among the 152 outbreaks with a confirmed food vehicle, a total of 165 food products tested positive; in seven outbreaks, two food products tested positive and in three outbreaks three food products were positive. In nine out of these 10 outbreaks, the pathogens were a combination of $B$. cereus, $C$. perfringens, and/ or $S$. aureus, and in the tenth outbreak, poultry tested positive for Salmonella Enteritidis and a composed product was positive for $B$. cereus. Furthermore, two food products (composed products) tested positive for both $B$. cereus and S. aureus.

Overall, red meat $(n=31)$ and composed products $(n=30)$ were the most common contaminated food products (Table 3). The pathogens most commonly identified in outbreaks caused by composed products, cereals/pasta/rice and, to a lesser degree red meat, were $B$. cereus, $C$. perfringens, and $S$. aureus. Other common pathogen-food pairs identified were Campylobacter-dairy, Salmonella-red meat, Salmonella Enteritidis-eggs, hepatitis A virusfruit/vegetables, norovirus-shellfish, and scombroid toxin-fish (tuna in 10/11 outbreaks).

\section{Discussion}

Twelve years of data from three surveillance pathways was utilised for a long-term descriptive analysis of foodborne outbreaks in the Netherlands. The majority of the outbreaks were registered at the NVWA by citizens. A much lower number of outbreaks were notified by PHS; however, since those reporting the outbreak were health care professionals, such as doctors and microbiologists, the chance of detecting a pathogen was much larger. A sizeable increase in reported outbreaks has been observed since 2015 , when reporting criteria were expanded to include outbreaks registered by the NVWA in which no food samples were taken. Although criteria were widened to reduce the under-reporting, the details of these additional outbreaks were limited, especially when the sources were unconfirmed.

Exploring trends per pathogen was not affected by the changes in reporting criteria, although only the annual number of outbreaks caused by norovirus, Salmonella and Campylobacter were high enough to be analysed. The emphasis for the registration and analytic developments of virus outbreaks from 2012 onwards led to an increase of reports of norovirus outbreaks, especially those with positive swabs. The largest food-borne outbreak recorded in the Netherlands occurred in 2012, caused by Salmonella Thompson in smoked salmon [11]. Based on the 1,149 reported cases, it was calculated that more than 21,000 people had been infected, 


\section{TABLE 3}

Number of contaminated food products found in outbreaks with a confirmed food vehicle, by aetiology and food commodity, the Netherlands, 2006-2019 $(n=165)$

\begin{tabular}{|c|c|c|c|c|c|c|c|c|c|c|c|c|}
\hline Pathogen & Fish & Shellfish & $\begin{array}{l}\text { Red } \\
\text { meat }^{a}\end{array}$ & Poultry & Eggs & Dairy & $\begin{array}{c}\text { Fruit/ } \\
\text { vegetables }\end{array}$ & $\begin{array}{l}\text { Cereals/ } \\
\text { pasta/ } \\
\text { rice }\end{array}$ & $\begin{array}{l}\text { Pastry/ } \\
\text { cookies }\end{array}$ & $\begin{array}{l}\text { Soup/ } \\
\text { sauce }\end{array}$ & $\begin{array}{l}\text { Composed } \\
\text { Product }^{\mathrm{b}}\end{array}$ & Total $^{c}$ \\
\hline Bacillus cereus & $o$ & 1 & 6 & 1 & 2 & 1 & 1 & 10 & 1 & 3 & 16 & 42 \\
\hline Clostridium perfringens & 0 & 0 & 2 & 3 & 0 & 0 & 1 & 0 & 0 & 0 & 5 & 11 \\
\hline Staphylococcus aureus & $o$ & 0 & 5 & 0 & 0 & 0 & 1 & 4 & 0 & 0 & 1 & 11 \\
\hline B.cereus and S. aureus & 0 & 0 & 0 & 0 & 0 & 0 & 0 & 0 & 0 & 0 & 2 & 2 \\
\hline Campylobacter spp. (total) & 0 & 0 & 1 & 3 & 0 & 5 & 0 & 0 & 0 & 0 & 1 & 10 \\
\hline Campylobacter fetus & 0 & 0 & 0 & 0 & 0 & 1 & 0 & 0 & 0 & 0 & 0 & 1 \\
\hline Campylobacter jejuni & 0 & 0 & 0 & 0 & $o$ & 3 & 0 & 0 & 0 & 0 & 0 & 3 \\
\hline Campylobacter spp. & 0 & 0 & 1 & 3 & 0 & 1 & 0 & 0 & 0 & 0 & 1 & 6 \\
\hline Listeria monocytogenes & 3 & 1 & 2 & 2 & 0 & 0 & 0 & 1 & 0 & 0 & 0 & 9 \\
\hline Salmonella spp. (total) & 1 & 1 & 12 & 5 & 6 & 2 & 2 & 0 & 0 & 0 & 2 & 31 \\
\hline Salmonella Enteritidis & 0 & 1 & 3 & 1 & 6 & 0 & 0 & 0 & 0 & 0 & o & 11 \\
\hline Salmonella Typhimurium & 0 & 0 & 5 & 0 & 0 & 2 & 0 & 0 & 0 & 0 & 0 & 7 \\
\hline Other Salmonella serotypes & 1 & 0 & 3 & 3 & 0 & 0 & 2 & 0 & 0 & 0 & 1 & 10 \\
\hline Salmonella spp. & 0 & 0 & 1 & 1 & 0 & 0 & 0 & 0 & 0 & 0 & 1 & 3 \\
\hline STEC (total) & 0 & 0 & 3 & 0 & 0 & 0 & 2 & 0 & 0 & 0 & o & 5 \\
\hline STEC 0104: $\mathrm{H}_{4}$ & o & o & o & o & 0 & o & 1 & o & 0 & 0 & o & 1 \\
\hline STEC 0157 & 0 & 0 & 3 & 0 & 0 & 0 & 1 & 0 & 0 & 0 & 0 & 4 \\
\hline Vibrio parahaemolyticus & 0 & 1 & 0 & 0 & 0 & 0 & 0 & 0 & 0 & 0 & 0 & 1 \\
\hline Hepatitis A virus & 0 & 1 & 0 & 0 & 0 & 0 & 4 & 0 & 0 & 0 & 0 & 5 \\
\hline Norovirus (total) & 0 & 21 & 0 & 0 & 0 & 0 & 1 & 0 & 2 & 0 & 3 & 27 \\
\hline Norovirus GI & 0 & 2 & 0 & 0 & 0 & 0 & 0 & 0 & 1 & 0 & 1 & 4 \\
\hline Norovirus GI and GII & 0 & 3 & 0 & 0 & 0 & 0 & 0 & 0 & 0 & 0 & 0 & 3 \\
\hline Norovirus GII & 0 & 4 & 0 & 0 & 0 & 0 & 0 & 0 & 0 & 0 & 1 & 5 \\
\hline Norovirus & 0 & 12 & 0 & 0 & 0 & 0 & 1 & 0 & 1 & 0 & 1 & 15 \\
\hline Scombroid toxin/histamine & 11 & 0 & 0 & 0 & 0 & 0 & 0 & 0 & 0 & 0 & o & 11 \\
\hline Total & 15 & 26 & 31 & 14 & 8 & 8 & 12 & 15 & 3 & 3 & 30 & 165 \\
\hline
\end{tabular}

GI: Genogroup I; GII: Genogroup II; STEC: Shiga toxin-producing E. coli.

a Red meat is beef and/or pork.

${ }^{b}$ Composed products are dishes with a mixture of ingredients, for example vegetables, meat, and/or rice.

'In seven outbreaks, two food products tested positive and in three outbreaks, three food products.

Rows in bold text indicate the subtotal for each particular pathogen or pathogen group. Rows that are not in bold are subgroups of a pathogen based on typing results. 
with an estimated total outbreak cost of EUR 7.5 million of which EUR 6.8 million was the cost-of-illness [13]. Strikingly, after this large outbreak, the number of Salmonella outbreaks dropped significantly without an obvious reason. Up to 2012, a decrease in cases was also seen in the sentinel Salmonella laboratory surveillance, but followed by a stabilisation afterwards [14]. For Campylobacter, a decrease in cases in the sentinel laboratory surveillance was observed since 2014, although this decrease seemed more prominent in the number of outbreaks than in the total number of cases [14].

A large proportion of the norovirus outbreaks were identified by positive environmental swabs, supported by confirmed norovirus in cases or reported symptoms pointing towards norovirus. Presence of norovirus on utensils and surfaces can point to an infected food handler who has contaminated food during preparation caused by flaws in hygiene measures [15]. Nevertheless, person-to-person transmission cannot be ruled out in these cases. In the confirmed food vehicle outbreaks of norovirus, 21 of 27 outbreaks were related to shellfish. The point of contamination of shellfish with viruses is most likely in the area where the seafood is farmed on account of sewage inlet [15]. The other six norovirus outbreaks with a confirmed food vehicle were more likely to have been caused by infected food handlers. Salmonella outbreaks with a confirmed food vehicle were most likely related to red meat, eggs (all S. Enteritidis), poultry meat and dairy, consistent with the main reservoirs for Salmonella and as reported in food-borne outbreak overviews of other countries worldwide [6,16-18]. A notable difference between Campylobacter versus Salmonella a nd norovirus was the number of cases per outbreak, which was much lower in Campylobacter outbreaks. Similar differences in number of cases per outbreak for these pathogens were reported in New South Wales, Australia and the United States $[6,18]$, whereas in the United Kingdom, the mean number of cases per outbreak did not differ significantly for Salmonella and $C$ ampylobacter [17]. An explanation for the smaller outbreaks could be the lack of growth of Campylobacter in food, in contrast to Salmonella [19]. Only in a small part of the Campylobacter outbreaks could a food product be confirmed, in which dairy (raw milk/ raw milk cheese) and poultry were most prominent. An attribution study estimated that $66 \%$ of the human Campylobacter infections in the Netherlands originated from chicken, $21 \%$ from cattle, $3 \%$ from sheep, and $0.3 \%$ from pigs [20]. In the United States, England and Wales, where larger numbers of Campylobacter outbreaks were recorded, poultry, dairy, water and composed foods were the most relevant sources $[6,17]$.

The toxin-producing bacteria $S$. aureus, C. perfringens and, in particular, $B$. cereus were other main pathogens in the confirmed food-borne outbreaks. These bacteria were detected in all food groups, except fish, but with a preference for composed food and cereals/pasta/rice. $B$. cereus is ubiquitously present in the environment and food products, $S$. aureus is typically found on skin and in the nasal passage and C. perfringens exists in soil, intestinal flora and animals [21-24]. Inadequate temperature management, such as slow or inadequate cooling and storage of food products at elevated temperatures between $10^{\circ} \mathrm{C}$ and $60^{\circ} \mathrm{C}$, may allow multiplication of the bacteria and production of toxins $[21,22,25]$. Poor hygiene and improper cleaning could introduce contamination of products at any stage from primary production up to serving the food. The number of viable $B$. cereus cells can be reduced when a product has been reheated, eliminating the bacteria [25]. However, toxins already present before reheating will remain and can cause disease. Although the majority of food-borne outbreaks caused by $B$. cereus show concentrations above $100,000 \mathrm{cfu} / \mathrm{g}$ in the contaminated product, outbreaks with concentrations between 1,000 and $100,000 \mathrm{cfu} / \mathrm{g}$ have also been reported [26]. In the present analyses, outbreaks with counts below 100,000 cfu/g for B. cereus, C. perfringens or $S$. aureus were classified as 'unknown causative agent'. This could have led to an underestimation of outbreaks caused by these toxin-producing bacteria, as another 55 outbreaks were within the range 1,000 and 100,000 $\mathrm{cfu} / \mathrm{g}$; this includes 39 outbreaks in which $B$. cereus was found in a food product, six outbreaks with $C$. perfringens, eight with $S$. aureus, and two with $B$. cereus and either $C$. perfringens or $S$. aureus (data not shown). Disease on account of these toxin-producing bacteria, which is symptomatically similar, was rarely confirmed in cases, as it is mostly short and self-limiting $[21,27,28]$. This causes a diagnostic deficit, as cases will rarely seek medical attention and no laboratory analyses are performed.

The majority of the outbreaks were registered at the NVWA, and mainly have restaurants/delis/cafeteria as the setting. This could indicate that, during an inspection by the food safety authority, inspectors should check whether the relevant requirements for food handling and preparation are met. On the other hand, these outbreaks are mainly reported by citizens and were often not pathogen-confirmed. In outbreaks in which the pathogen was confirmed in the cases, our data indicates that the overall percentage of public eating places was lower and that private homes were also a setting for outbreaks. A tendency to detect or report an outbreak in a public eating place more frequently as compared with home can, therefore, not be ruled out.

Contamination of food can occur at any point from farm to table. The outbreaks with positive environmental swabs and those caused by the three toxin-producing bacteria, mainly found in composed products and cereals/pasta/rice, were most likely the result of improper hygiene, handling, storage and preparation in the last stage before consumption. Shellfish (norovirus, hepatitis A virus), red meat (Salmonella, STEC), eggs (Salmonella), dairy (Campylobacter, Salmonella) 
and fruit/vegetables (Salmonella, STEC, hepatitis A virus) are products with highest risk of being contaminated during the production process. The risk of people becoming infected arises when these products are eaten raw or undercooked, as thorough heating would reduce or eliminate the pathogens. High production standards including control measures must be in place to reduce the risk. Even when some foods, e.g. red meat or poultry, are eaten after thorough heating, improper food handling during preparation could lead to cross contamination and thus illness [29]. However, in our study, the moment of contamination could not be analysed with the current information.

Furthermore, the pathogen causing the disease remained unknown in the majority of the outbreaks (88.2\%), consistent with observations from New South Wales, Australia [18]. Several factors contribute to this gap. Firstly, most pathogens have an incubation period of at least several days [30]. Often, leftovers of the implicated food items will no longer be available for testing when disease symptoms arise and are reported. This is amplified when reporting is done after the pathogen is detected in cases, since analysis can take several days. The probability that the batch of the implicated food item is no longer available increases with an increasing time window. Furthermore, the incubation period introduces recall bias, which could lead to incorrect designation of a certain food item as the possible contaminated food product, especially in small outbreaks with cases, i.e. members of one household, that share more than one common food item. This is exacerbated by the inclusion of outbreaks reported at the NVWA directly by citizens. Another possibility is that food was implied as source of the infection, but in reality was caused by person-to-person spread.

Food is produced and transported globally. When a food product is contaminated early in the food production chain, cases can spread over a large geographical area. A national surveillance system including sequence data of human isolates offers the opportunity to follow the different strains seen within the country and detect even small clusters that spread nationwide. Such pathogen-based laboratory surveillance systems are developed for Salmonella, L. monocytogenes, STEC and hepatitis A virus in the Netherlands, which has led to the identification of several national outbreaks that otherwise would not have been seen at all or not caught until a much later stage. An isolate-based surveillance system is currently developed for Campylobacter, which shows a stable high incidence as well as disease burden, indicating that efforts to reduce this pathogen at primary production or during the handling and processing phase is not effective. Identifying national clusters increases the opportunity for case-control studies and source tracing by which potential sources can be identified and possibly be eliminated, thereby reducing the disease burden. In addition, the national system currently in place also opens the opportunity to communicate with other, surrounding countries to determine whether an outbreak is seen internationally. In some cases, this can even lead to a joint investigation, as occurred with several outbreaks in our overview, e.g. STEC in lettuce together with Iceland [31], Salmonella Newport in bean sprouts together with Germany [32], and Salmonella Enteritidis in eggs in a joint European investigation [33].

\section{Conclusions}

Usage of different pathways to monitor food-borne outbreaks aids insight in the occurrence of these outbreaks. PHS register local outbreaks, national disease-specific surveillance systems detect outbreaks dispersed over a larger area, and citizens report outbreaks that otherwise would have been missed. Analysis of 12 years of food-borne outbreaks reveals the persistent occurrence of these outbreaks in the Netherlands. A multiplicity of pathogens can cause illness via a vast array of food products, complicating control and elimination of foodborne illness. Contamination during the production process, consumption of raw products, and improper hygiene, handling, storage and preparation are the main underlying factors that could be addressed to reduce the number of food-borne outbreaks. Overall, norovirus, Salmonella and Campylobacter appeared to be the most prevalent pathogens related to foodborne outbreaks. Additionally, specific connections were seen between pathogens and food commodities. These results will guide in future outbreak investigations to focus the search to the source where possible.

\section{Acknowledgements}

The authors thank the staff members of the regional public health services, diagnostic laboratories and the Dutch Food and Consumer Product Safety Authority for investigating and reporting the analysed food-borne outbreaks.

Funding statement: This study received no specific grant from any funding agency.

\section{Conflict of interest}

None declared.

\section{Authors' contributions}

IF: collected and analysed the food-borne outbreak data, and drafted the manuscript. ISFJ and BW: checked and complemented data of food-borne outbreaks, revised the manuscript and approved the final manuscript. EF: supervised the surveillance and this study, contributed actively to the manuscript and approved the final manuscript.

\section{References}

1. Hara-Kudo Y, Takatori K. Contamination level and ingestion dose of foodborne pathogens associated with infections. Epidemiol Infect. 2011;139(10):1505-10. https://doi. org/10.1017/S095026881000292X PMID: 21205441

2. Todd ECD, Grieg JD. Viruses of foodborne origin: A review. Virus Adaptation and Treatment.2015;7:25-45. https://doi. org/10.2147/VAAT.S50108 
3. Carter MJ. Enterically infecting viruses: pathogenicity, transmission and significance for food and waterborne infection. J Appl Microbiol. 2005;98(6):1354-80. https://doi. org/10.1111/j.1365-2672.2005.02635.x PMID: 15916649

4. Pijnacker R, Friesema IHM, Mughini Gras L, Lagerweij GR, Van Pelt W, Franz E. Disease burden of food-related pathogens in the Netherlands, 2018. Bilthoven: RIVM; 2019. Available from: https://www.rivm.nl/bibliotheek/rapporten/2019-0086.pdf

5. Havelaar AH, Haagsma JA, Mangen MJ, Kemmeren JM, Verhoef LPB, Vijgen SMC, et al. Disease burden of foodborne pathogens in the Netherlands, 2009. Int J Food Microbiol. 2012;156(3):231-8. https://doi.org/10.1016/j. ijfoodmicro.2012.03.029 PMID: 22541392

6. Dewey-Mattia D, Manikonda K, Hall AJ, Wise ME, Crowe SJ. Surveillance for Foodborne Disease Outbreaks - United States, 2009-2015. MMWR Surveill Summ. 2018;67(10):1-11. https:// doi.org/10.15585/mmwr.ss6710a1 PMID: 30048426

7. Ebel ED, Williams MS, Cole D, Travis CC, Klontz KC, Golden NJ, et al. Comparing Characteristics of Sporadic and OutbreakAssociated Foodborne Illnesses, United States, 20042011. Emerg Infect Dis. 2016;22(7):1193-200. https://doi. org/10.3201/eid2207.150833 PMID: 27314510

8. Brown LG, Hoover ER, Selman CA, Coleman EW, Schurz Rogers $\mathrm{H}$. Outbreak characteristics associated with identification of contributing factors to foodborne illness outbreaks. Epidemiol Infect. 2017;145(11):2254-62. https://doi.org/10.1017/ So950268817001406 PMID: 28689510

9. Dutch Government. Warenwetbesluit Bereiding en behandeling van levensmiddelen. [Commodities Act Decree Preparation and handling of foodstuffs]. The Hague: Overheid.nl. [Accessed: 10 May 2021]. Dutch. Available from: https://wetten.overheid.nl/ BWBRoo05758/2019-12-14

10. European Commission. Regulation (EC) No 2073/2005 on microbiological criteria for foodstuffs. Brussels: European Commission. [Accessed: 10 May 2021]. Available from: https://eur-lex.europa.eu/legal-content/EN/ $\mathrm{ALL} /$ ? uri=CELEX\%3A32005R2073

11. Friesema I, de Jong A, Hofhuis A, Heck M, van den Kerkhof $\mathrm{H}$, de Jonge $\mathrm{R}$, et al. Large outbreak of Salmonella Thompson related to smoked salmon in the Netherlands, August to December 2012. Euro Surveill. 2014;19(39):20918. https://doi. org/10.2807/1560-7917.ES2014.19.39.20918 PMID: 25306981

12. Van Duynhoven YT, Isken LD, Borgen K, Besselse M, Soethoudt K, Haitsma O, et al. A prolonged outbreak of Salmonella Typhimurium infection related to an uncommon vehicle: hard cheese made from raw milk. Epidemiol Infect. 2009;137(11):1548-57. https://doi.org/10.1017/ So950268809002337 PMID: 19296867

13. Suijkerbuijk AWM, Bouwknegt M, Mangen MJ, de Wit GA, van Pelt W, Bijkerk P, et al. The economic burden of a Salmonella Thompson outbreak caused by smoked salmon in the Netherlands, 2012-2013. Eur J Public Health. 2017;27(2):325-30. PMID: 27836967

14. Vlaanderen F, Cuperus T, Keur I, De Rosa M, Rozendaal H, Friesema I, et al. Staat van Zoönosen 2019. [State of Zoonoses 2019]. Bilthoven: RIVM; 2020. Dutch. Available from: https:// www.rivm.nl/bibliotheek/rapporten/2020-0130.pdf

15. Hardstaff JL, Clough HE, Lutje V, McIntyre KM, Harris JP, Garner $P$, et al. Foodborne and food-handler norovirus outbreaks: a systematic review. Foodborne Pathog Dis. 2018;15(10):589-97. https://doi.org/10.1089/fpd.2018.2452 PMID: 30109958

16. Mughini-Gras L, Enserink R, Friesema I, Heck M, van Duynhoven $Y$, van Pelt W. Risk factors for human salmonellosis originating from pigs, cattle, broiler chickens and egg laying hens: a combined case-control and source attribution analysis. PLoS One. 2014;9(2):e87933. https://doi.org/10.1371/journal. pone.0087933 PMID: 24503703

17. Gormley FJ, Little CL, Rawal N, Gillespie IA, Lebaigue S, Adak GK. A 17-year review of foodborne outbreaks: describing the continuing decline in England and Wales (1992-2008). Epidemiol Infect. 2011;139(5):688-99. https://doi.org/10.1017/ S0950268810001858 PMID: 20696086

18. Franklin N, Hope K, Glasgow K, Glass K. Describing the epidemiology of foodborne outbreaks in New South Wales from 2000 to 2017. Foodborne Pathog Dis. 2020;17(11):701-11. https://doi.org/10.1089/fpd.2020.2806 PMID: 32397759

19. Pebody RG, Ryan MJ, Wall PG. Outbreaks of campylobacter infection: rare events for a common pathogen. Commun Dis Rep CDR Rev. 1997;7(3):R33-7. PMID: 9080726

20. Mughini Gras L, Smid JH, Wagenaar JA, de Boer AG, Havelaar AH, Friesema IH, et al. Risk factors for campylobacteriosis of chicken, ruminant, and environmental origin: a combined case-control and source attribution analysis. PLoS One. 2012;7(8):e42599. https://doi.org/10.1371/journal. pone.0042599 PMID: 22880049
21. Stenfors Arnesen LP, Fagerlund A, Granum PE. From soil to gut: Bacillus cereus and its food poisoning toxins. FEMS Microbiol Rev. 2008;32(4):579-606. https://doi.org/10.1111/j.15746976.2008.00112.x PMID: 18422617

22. Abebe E, Gugsa G, Ahmed M. Review on major food-borne zoonotic bacterial pathogens. J Trop Med. 2020;2020:4674235. https://doi.org/10.1155/2020/4674235 PMID: 32684938

23. Fisher EL, Otto M, Cheung GYC. Basis of virulence in enterotoxin-mediated staphylococcal food poisoning. Front Microbiol. 2018;9:436. https://doi.org/10.3389/ fmicb.2018.00436 PMID: 29662470

24. Heikinheimo A, Lindström M, Granum PE, Korkeala H. Humans as reservoir for enterotoxin gene--carrying Clostridium perfringens type A. Emerg Infect Dis. 2006;12(11):1724-9. https://doi.org/10.3201/eid1211.060478 PMID: 17283623

25. Rouzeau-Szynalski K, Stollewerk K, Messelhäusser U, Ehling-Schulz M. Why be serious about emetic Bacillus cereus: Cereulide production and industrial challenges. Food Microbiol. 2020;85:103279. https://doi.org/10.1016/j. fm.2019.103279 PMID: 31500702

26. EFSA Panel on Biological Hazards (BIOHAZ). Risks for public health related to the presence of Bacillus cereus and other Bacillus spp. including Bacillus thuringiensis in foodstuffs. EFSA J. 2016;14(7):e04524.

27. Messelhäußer U, Ehling-Schulz M. Bacillus cereus-a multifaceted opportunistic pathogen. Curr Clin Microbiol Rep. 2018;5(2):120-5. https://doi.org/10.1007/s40588-018-0095-9

28. Mallozzi M, Viswanathan VK, Vedantam G. Spore-forming Bacilli and Clostridia in human disease. Future Microbiol. 2010;5(7):1109-23. https://doi.org/10.2217/fmb.10.60 PMID: 20632809

29. Iulietto MF, Evers EG, National Institute for Public Health and the Environment (RIVM), The Netherlands. Modelling and magnitude estimation of cross-contamination in the kitchen for quantitative microbiological risk assessment (QMRA). EFSA J. 2020;18(Suppl 1):e181106. PMID: 33294045

30. Chai SJ, Gu W, O'Connor KA, Richardson LC, Tauxe RV. Incubation periods of enteric illnesses in foodborne outbreaks, United States, 1998-2013. Epidemiol Infect. 2019;147:e285. https://doi.org/10.1017/S0950268819001651 PMID: 31587689

31. Friesema I, Sigmundsdottir G, van der Zwaluw K, Heuvelink A, Schimmer B, de Jager C, et al. An international outbreak of Shiga toxin-producing Escherichia coli $0_{157}$ infection due to lettuce, September-October 2007. Euro Surveill. 2008;13(50):18-22. https://doi.org/10.2807/ese.13.50.19065 en PMID: 19087865

32. Bayer C, Bernard H, Prager R, Rabsch W, Hiller P, Malorny B, et al. An outbreak of Salmonella Newport associated with mung bean sprouts in Germany and the Netherlands, October to November 2011. Euro Surveill. 2014;19(1):20665. https://doi. org/10.2807/1560-7917.ES2014.19.1.20665 PMID: 24434173

33. Pijnacker R, Dallman TJ, Tijsma ASL, Hawkins G, Larkin L, Kotila SM, et al. An international outbreak of Salmonella enterica serotype Enteritidis linked to eggs from Poland: a microbiological and epidemiological study. Lancet Infect Dis. 2019;19(7):778-86. https://doi.org/10.1016/S14733099(19)30047-7 PMID: 31133519

\section{License, supplementary material and copyright}

This is an open-access article distributed under the terms of the Creative Commons Attribution (CC BY 4.0) Licence. You may share and adapt the material, but must give appropriate credit to the source, provide a link to the licence and indicate if changes were made.

Any supplementary material referenced in the article can be found in the online version.

This article is copyright of the authors or their affiliated institutions, 2022. 